This is the original manuscript of the article. The Version of Record of this manuscript has been published at the Journal of Intervention and Statebuilding, Volum 14, 2020 - Issue 3, Taylor and Francis, at:

https://www.tandfonline.com/doi/abs/10.1080/17502977.2019.1663987?.journalCode $=$ risb20

This manuscript is deposited under the terms of the Creative Commons Attribution-

NonCommercial License (http://creativecommons.org/licenses/by-nc/4.0/), which permits non-commercial re-use, distribution, and reproduction in any medium, provided the original work is properly cited.

Article title: Prevention From Afar: Gendering Resilience and Sustaining Hope in PostUNMIL Liberia

Article DOI: https://doi.org/10.1080/17502977.2019.1663987

Authors: Pol Bargués-Pedreny and Maria Martin de Almagro

Journal title: Journal of Intervention and Statebuilding 


\title{
Prevention from Afar: Gendering Resilience and Sustaining Hope in post-UNMIL Liberia
}

\begin{abstract}
This article argues that resilience programmes in conflict-affected areas of limited statehood could be understood as much as an effort to equip vulnerable populations with tools to mitigate the effects of poverty, discrimination, lack of opportunities and manage gender inequalities than as an opportunity for the international community to prolong their interventions, consolidate local partnerships and sustain hope. We demonstrate our argument through an examination of the implementation in post-UNMIL Liberia of the 'Spotlight Initiative', a new multi-year multimillion programme of the European Union (EU) and the United Nations (UN) focused on the complete elimination of harmful practices and violence against women.
\end{abstract}

Key words: resilience, prevention, gender, EU, Spotlight Initiative, Liberia

\section{Introduction}

On 20 September 2017, the EU and the UN launched the Spotlight Initiative with the ambitious goal of 'eliminating all forms of violence against women and girls' (VAWG) around the world. Known to be a Gender Equality and Women's Empowerment champion, EU Commissioner for International Cooperation and Development, Neven Mimica, proposed to the UN the launch of a global initiative that would go further than gender mainstreaming actions and that would send a strong (financial) signal of EU commitment to gender equality (Interview \#3). Backed by an initial 500 million euros from the EU, the Initiative provides large-scale, continued and targeted support to countries and regions in their fight against sexual and gender-based violence (SGBV), promotes multi-stakeholder partnerships with international, national and local organisations and is grounded in the 2030 Agenda for Sustainable Development. It also advances a 'new way of working' that brings together all relevant UN agencies, funds and programmes, the EU, its civil society and government partners, and a conglomerate of local groups, as diverse as autonomous women's organisations, grassroots organisations, the media, academia and the private sector (EU and UN 2018, 9). It is a comprehensive endeavour that is concerned with renovating social norms and augmenting political and economic opportunities to women, chiming with resilience approaches that are context sensitive and build on local resources and initiatives (Joseph and Juncos, 2019).

Liberia has been chosen as one of the beneficiary countries of the African regional programme of the Spotlight Initiative. It is an interesting case study because, although the UN Peacekeeping mission closed its doors in March 2018, just some months after Presidential elections were successfully organised in the country, the international community has not exited. Instead, the new Liberia Transition Multi-Partner Trust Fund has served as a pooled funding 
mechanism for the achievement of the Agenda 2030 and maintains peacebuilding activities by the UN Country Team. Indeed, the terms of reference of the Fund indicate that the the lives of many women are particularly insecure owing to societal inequality and sexual and gender-based violence, further weakening social cohesion in communities' (UN 2017, 3).

The literature examining gender equality and gender mainstreaming policies have noted a growing commitment to include gender analysis and sensibilities in underdeveloped and postconflict spaces intervened upon, albeit have been critical of the instruments and policies being implemented (Deiana and Mcdonagh 2018; Guerrina, Chappell, and Wright 2018; Guerrina and Wright 2016). For example, some studies show how formal institutions in societies intervened upon have remained controlled and dominated by men from elite groups, while disregarded women and feminist organisations and networks (Pratt and Richter-Devroe 2011; Ryan and Basini 2017). Others have seen how gender-sensitive policies have often been narrowly understood as counting with more women in decision-making, neglecting the links between gender and peace, security and economic and social equality (Kirby and Shepherd 2016; Martin de Almagro 2018). As Martin de Almagro and Ryan (2019) have recently summed up, there is a failure to account for the materiality of women's economic empowerment, as well as to undo the discourses that curtail women's access to resources and institutions. These studies are embedded in a broader critique of international intervention. There is a wide consensus that current resilience and sustaining peace approaches, despite the rhetoric that they attempt hybrid and inclusive processes, are still led by domineering external institutions and liberal values, thus undermining organic and non-liberal solutions (Ejdus and Juncos 2018; Randazzo 2016; Read, Taithe, and Mac Ginty 2016; Wallis, Jeffery, and Kent 2016).

While agreeing with most of these observations, this article proposes to examine current interventions and gender-sensitive programmes from a different angle. For what is striking about the first annual report of the Spotlight Initiative is the Herculean tasks needed to counter VAWG, seen as a 'global epidemic', 'one of the most rampant and devastating human rights violation in the world', that leaves tragic stats like 'more deaths are caused by domestic violence... than civil wars', ' $35 \%$ of women have experienced violence, as high as $70 \%$ in some countries', or 'almost half of female homicide victims were killed by a family member' (EU and UN, 2018: 11, 13). Resolutely, Spotlight recommends legislative and policy frameworks that respect human rights and pursue gender equality, strengthen governmental institutions and ensure that they are gender responsive, promote quality services and increase women's access to those services. It also invests in the production, collection and analysis of data to inform policymaking and budgeting (EU and UN, 2018: 23). Furthermore, Spotlight attempts to strengthen 'autonomous women's movements' and work through the inter-subjective settings of societies, affecting 'social norms, attitudes and behaviours that perpetuate negative stereotypes and discrimination', as well as 'redefin[ing] masculinity and foster[ing] acceptance of gender equality' (EU and UN, 2018: 15). Why is it that despite the impossible, unmanageable, almost interminable challenges lying ahead, there is such an institutional support and impetus to the programme? Why is it that the report is ornamented with enthusiastic quotes by the UN Secretary General and other high officials that announce: 'a new beginning', a 'historic' opportunity, to 'seize the momentum' and 'the right time' for the Initiative?

In this article we suggest that Spotlight is indicative of a broader tendency to sustain interventions across time, indicating that the process is more important than the outcome. What matters is not so much the direction that is taken but 'leaving no one behind', understood as a process were increasingly more women can be included (EU and UN, 2018: 24). The multi-trust fund offers an argumentation of a complex temporality (Cavelty et al., 2015), where the 
international donor community discovers that the past offers little guidance and the future is radically uncertain and full of risks, thus requiring multifarious actions and long-time investment. It is 'hope' that best combines the disenchantment with the state-of-affairs of the present with the expectancy of living a better tomorrow if one keeps on exploring (Lindroth and SinevaaraNiskanen, 2019). In Liberia, building resilient communities therefore becomes a discourse of coping with whatever comes in the present to get ready for a brighter future that never arrives.

Spotlight should be contextualized with broader framings of sustaining peace and resilience in areas of limited statehood (see further the project EU-LISTCO www.eu-listco.net). For example, similar to the twin resolutions of the General Assembly (70/262) and Security Council (2282), which emphasized the need to 'work better together to sustain peace at all stages of conflict and in all its dimensions', including prevention tasks long beforehand the outbreak of the conflict (UN, 2018a: 1), Spotlight favours a continued engagement which gradually adjusts to coming vicissitudes and uncertainties. Also, similar to other interventions of resilience, which understand it as means rather than as end (EC, 2017: 23), Spotlight is separated from the goals of ending a war or building a peace, thus avoiding the pressures and constraints of a "final judgement".

The analysis of Spotlight in Liberia (LSI) will be used as an example to think how the quest for gender inclusivity, which requires solid partnerships and multiple prevention tasks, legitimises a protracted intervention. Although it may be too soon to draw some final conclusions of this incipient programme, the paper ends by foreseeing two negative implications. The first is that women continue to lack autonomy, as they are seen as mere implementers of a programme that cannot be resisted. The second is that the EU and UN increasingly deny their responsibility. In an astute manoeuvre, Liberian culture appears to be the problem and the source of the solution, while international agencies are considered indispensable and continue to supervise free from fault.

This paper draws on two sets of data. First, a set of official documents constitutes our written material corpus. The material corpus is composed of 20 documents. These include strategic documents such as the EU Global Strategy and the Strategic Approach to Resilience in the EU's External Action, as well as programatic ones, such as all the UN reports on the Spotlight initiative related to Liberia, including the Spotlight Liberia country program document, the Spotlight Africa region program document, as well as the general ones, such as the Spotlight narrative report and the 2018 Spotlight annual report. All these Spotlight documents are freely available under the Multi-Partner Trust Fund Office website: http://mptf.undp.org/factsheet/fund/SIF00.

Second, we conducted seven in-depth interviews with EU staff involved in the planning and operationalization of the Spotlight Initiative, in Brussels, and also at the EU delegation in Liberia. Additionally, we had two informal conversations with EU staff in Liberia. We did not hold any interviews with women beneficiaries of Spotlight. There are good reasons for this. First, the aim of the article is to draw attention back to the conventional centres of global governance: the UN and the EU. Here, picking up from Louise Chappell, Meryl Kenny and Fiona Mackay (2010), as well as Laura Shepherd's work (2017), we are committed to understanding how these policy institutions and their representational practices can have unintended consequences when designing what could be considered as rather progressive agendas. Second, Liberia's Spotlight program was only launched on June $18^{\text {th }} 2019$ and the project implementation has barely started. Local perceptions of direct and indirect beneficiaries and the results of the project will be the object of a related research project. 
As Kronsell indicates, interviews are an important source of information because they can provide an in-depth, detailed account of how gendered practices are actually carried out within institutions as well as of how gendered identities are constructed and contested' (2006: 121). Methodologically, the inclusion of interview data alongside policy documents allows for the analysis of a wider range of discursive practices and variances, while revealing ambiguities and tensions. This method is particularly useful in order to explore not why the EU as the intellectual and financial mother of Spotlight evolves from a foreign policy strategy of peacebuilding intervention to sustained preventative engagement, but rather how intervention becomes persistent and long-term, as well as through which policy practices and commitments. The paper is structured into three sections. The first reviews the EU approach to resilience and contrasts it with earlier concerns with statebuilding. The second examines how resilience has been gendered and introduces the case of Spotlight. The third section critically examines the application of Spotlight in Liberia.

\section{From Statebuilding to Resilience}

In June 2017, the EU and member states established the 'Joint Communication on a Strategic Approach to Resilience in the EU's External Action'. Drawing on the EU Global Strategy (EUGS) of a year earlier, this policy framework was meant to guide the concrete actions of EU practitioners when strengthening state and societal 'resilience' abroad (EC 2017, 2). Albeit decisive mechanisms and instruments were established in 2017 to enhance cooperation and coherence and develop a European Security and Defence Union to jointly build and deploy defence capabilities (Tocci, 2018), the EU certainly did not shift abruptly towards a new paradigm of external action that year. At least since the Lisbon Treaty signature in 2009, the Union has advanced toward approaches in the fields of peacebuilding, development or climate change mitigation that emphasise partnerships - with international institutions as much as local partners - and long-term engagements to promote sustainable progress (EC, 2013). The idea of resilience has cohered around a set of governing rationalities that shift away from top-down and statist governance models towards bottom-up engagements that govern from a distance, facilitating rather than imposing, embedding norms and values, and encouraging citizens to adapt to crises and risks (Chandler, 2014; Joseph, 2018).

The key to interpret the strategic approach to resilience is to compare it with the set of understandings of statebuilding frameworks of the decade of 2000s, which resulted in operations that institutionalized a negative peace and built depoliticised states that were estranged from the people, their cultures and histories (Campbell et al., 2011; Lemay-Hébert, 2011). What is striking is the emphasis of the EU on how much the world has been transformed. According to the EU, policies must be operationalized against the backdrop of a 'rapidly changing', 'more connected, contested and complex global environment', 'a fluid landscape of global challenges and risks', and 'chronic vulnerability and fragility in the neighbourhood' that exacerbates 'economic shocks', 'demographic, climate change, environmental or migratory challenges' (EC, 2017: 2-3; see also, EEAS, 2015). This contrasts with approaches that focused on democracy promotion and statebuilding, where the problems identified were much more concrete, such as absence of free and fair elections, authoritarian leaders, or the lack of strong rule of law institutions (for an overview, see Paris and Sisk, 2009).

The idea of an unfathomable and complex world certainly responds to a geo-strategic analysis of international relations, where the EU and its liberal values are contested both externally - in a multipolar world, where Russia and China awake and the US isolates from multilateral forums - 
and internally - with economic and migration crises, the United Kingdom leaving the Union and the rise of Euro-sceptic right-wing parties. More fundamentally, it reveals a crisis of meaning and purpose, a blurry vision and low expectations, a far cry from the EUGS of 2003, when the EU sought to shape the world according to its image and likeness (Morillas, 2019). Today's paradigm of resilience is a much more modest and pragmatic approach to conducting external action, which enables the EU to respond to the challenges of a complex world while relinquishing responsibility to other countries (Juncos, 2017; Wagner and Anholt, 2016). Although the focus of this article is on the EU, as the ideologist and funder of the Spotlight Initiative, it is important to note that resilience has broader resonances, for example, at the UN policy level, where peacebuilding is also being reinterpreted as a process of sustainability and adaptation to a world in flux (de Coning, 2018).

Within resilience policy frameworks, at least discursively, the state has dropped as the main referent of the intervention, being replaced by the societal, community and individual levels. The idea for the EU is to foster capacity building at different institutions and scales of governance and involving a wide variety of local actors (Hirblinger and Landau, 2018). Instead of thinking of fragile or failed states whose collapsed central government needs to be restored, there is inclination to conceive of diffused and overlapping spaces of limited statehood with multiple stakeholders facilitating security, goods and services (Risse and Börzel, 2018). Rather than assuming that the political systems of post-conflict societies are 'an empty shell' that can be rebuilt from scratch (Lemay-Hébert, 2011), the EU is committed to 'identifying and building upon existing positive sources of resilience' (EC 2017, 23). Partnerships are no longer limited to agreements with actors who lean toward liberal goals or are donor darlings (Turner, 2011), but plural and complex to pursue a 'more tailor-made and differentiated relationships with partners' (EC 2017, 15).

The EU considers women a privileged partner in the community level that can be decisive in peace efforts, as will be explored further in the next section. The European Council affirms that the Women, Peace and Security agenda of the United Nations, as well as gender equality and women's empowerment, should continue to be mainstreamed into all policy areas, including security, defence, development and crisis management (EUGS 2016). The Strategic Approach to Resilience also notes that violent conflict and disasters affect women and men differently, while recognises that women contribute decisively to conflict prevention and resolution tasks:

Women and girls can also play an active and important role in contributing to societal resilience that can underpin peace. Ensuring that women and girls are well informed and actively participate in peace building and recovery efforts not only ensures that their specific needs and capacities are taken into consideration, but can also create a window of opportunity for social change, by challenging traditional gender roles and gender-based discrimination (EC 2017, 8).

Gender inequality is clearly identified as an obstacle to societal resilience; as if empowered, women can do wonders at the community level. While we do not question the prolific literature that establishes links between women's empowerment and development outcomes, a central argument in the discourse of the EU here is that women play a fundamental role in societal resilience. Reducing gender inequalities is therefore not only a goal in itself, but also will be instrumental for the achievement of many other society-wide outcomes. This implies first that broad empowerment and action on gender and sexual-based violence can change societies and power structures and second, that these changes would be positive, as if a community run by women would look very different (Duflo, 2012; Shepherd, 2011). Understanding women as 
positive actors and putative agents is not only unreflexive with regards to gender identity, but also obviates the ways in which women's agency can be harmful. For example, it is women who practice FGM on other women.

By gendering conflict and peace-related responses, the EU moves the weight of the intervention to the informal spheres of countries intervened upon (Hughes and Pupavac, 2005). Earlier operations assumed that peace would take root provided that international agencies could implement reforms and construct legitimate and capable governmental institutions and the rule of law after the war. State institutions appeared to be the key to keep the peace and, as soon as they were functioning, an inclusive and reunited society could be consolidated (Ghani and Lockhart, 2008). Today, quite differently, engagement at the community level both diversifies and multiplies the number of duties and actions. Uncertain outcomes accompany any policy initiative, while risks of doing harm force peacebuilders to be careful and practice tailor made interventions (Tull, 2018). Strategies of resilience demand a much more comprehensive and continued approach.

Indeed, the Strategic Approach to Resilience emphasises the importance of sustaining intervention for a long period of time. Furthermore, the EU's incipient 'integrated approach to external conflicts and crises', and the conclusions of which were released on January 22, 2018, put forward a holistic and uninterrupted engagement:

[The Integrated Approach] is applied at the local, national, regional and global levels (multi-level) as needed and throughout all phases of the conflict - including protracted conflicts and crises - (multi-phase) in prevention, crisis response, stabilisation and longerterm peacebuilding, in order to contribute to sustainable peace (Council of the EU 2018, 2).

In both reports, peace and resilience need to be sustained across time, without assuming a beginning or end of the intervention. Two examples taken from the conclusion of the two reports will prove the point. First, resilience and peace are linked to early action and prevention and, second, both are understood as means rather than ends, focused on a complex process where the references to specific outcomes or results decline.

First, even if prevention does not mobilise the attention of television cameras, win recognition or set ephemerides, the logic is that 'preventing conflicts is more efficient and effective than engaging with crises after they break out. Once a conflict does erupt, it typically becomes ever more intractable over time', as explained by the EUGS (2016: 29). This does not imply a return to traditional framings of prevention that were committed to removing threats to international peace, settling inter-state disputes and developing friendly relations via diplomatic action. Nothing of the sort appears to be the case in today's international framings of prevention (UN, 2018c). Instead, prevention is understood much more modestly than before, as an attempt to reduce the inevitable 'effects' and impact of crisis and conflicts (Chandler 2015). It is, indeed, a mechanism to avoid that the situation worsens, that pressures reach a tipping point, or that violence does not hit vulnerable populations again (EC 2017, 24). Early action responses require practitioners that sleep little; an intervention that never stops.

Second, 'strengthening resilience is a means not an end' (EC 2017, 23). For there is recognition that progress is not a linear process, where crises are unpredictable and outcomes constantly deviate from initial intentions. Instead of bringing external know-how and expertise to the field, resilience and sustaining peace require 'risk-informed programming' and 'building 
flexibility and adaptability to change into programme design from the outset' (EC 2017, 24). The focus on a process of continuous revision and adaptation implies that the goals are adjusted over time, while the end is continually postponed (Bargués-Pedreny, 2018). It also implies that the outcomes of intervention depend less on knowledge and will. Sustaining peace appears similar to sustaining hope. As shown in the photo of the cover of the UN conflict prevention report, it is like placing a candle in a religious site and expecting that events will turn out well (UN, 2018b, for another photo with similar message, see 2018c: 2). As the past cannot be used for guidance and the future is unpredictable, hope dies last.

The impression for practitioners is that sustaining peace is more about sustaining than literally about peace, more about hope than certainty (Interview \#3). The EU's 'all-hazard approach, bringing together analysis at regional, state, organisational community and individual level' seems more complete than ever before and attuned to complex interconnections, interdependencies and hybrids but is not literally about achieving resilience or peace (EC 2017, 24). Indeed, approaches that emphasise prevention and non-linear processes favour sustained engagements, hybrid responses and partnerships over resolutions, results and international withdrawal. As the Spotlight example shows, today's interventions start without end in sight, after peacekeeping missions finish. Strikingly, these sustained engagements depend on a peculiar gendering of interventions.

\section{Gendering Resilience: Leaving No One Behind?}

The fact that resilience is perceived as a new, softer security paradigm, focusing on societies, livelihoods and vulnerabilities have led some researchers to contrast its gendered nature with the masculinized discourse on global threats and managerial solutions of liberal peace (Hunter, 2016; Rothe, 2017). As exemplified in the Strategic approach to Resilience, the EU shows a new sensitivity to gendering the experiences of human-made or natural catastrophes, as they lead to different vulnerabilities of women and men. In particular, women are seen as suffering more, but also as important agents of change due to the tacit knowledge gained through personal experiences at the household (Kristjanson et al., 2017). Gender equality and women empowerment policies are therefore 'at the centre of the new approach to EU external action, at the heart of our policy work' (Interview \#4).

There has been extensive literature on the implementation of gender equality and gender mainstreaming policies inside the EU (Cavaghan, 2017; Guerrina, 2005; Hoskyns, 1996; Lombardo and Meier, 2006; Verloo, 2007). Research has also investigated the gendered impacts of EU policies and external gender equality promotion in security and in development policies (David and Guerrina, 2013; Debusscher, 2011; Deiana and Mcdonagh, 2018; Guerrina et al., 2018; Guerrina and Wright, 2016). The scholarship that analyses gender mainstreaming in Common Security and Defence Policy (CSDP) uniformly claims that although the EU has been clear in its commitment to gender mainstreaming, little has been materialised in practice. Some reckon that this is due to lack of strategic planning and robust institutional support (Olsson and Gizelis, 2015), while others note that it is the absence of feminist actors and feminist networks in the European External Action Service (EEAS) and in CSDP that has limited the implementation of gender policies (Guerrina et al., 2018; Guerrina and Wright, 2016). A third group of scholars suggest that there is resistance to acknowledge the essential linkages between gender, peace and security in peacekeeping and post-conflict transition and that the implementation of the Women, Peace and Security agenda in CSDP and in EU missions is considered as just an addendum and 
not as essential for the achievement of the EU objectives (Deiana and Mcdonagh, 2018). The literature on gender equality and gender mainstreaming in EU development policy also reaches similar conclusions: while there have been some progress on systematic technical assistance and capacity building to developing countries, results are still far from having the transformative potential sought and fall short of EU normative predisposition to guarantee gender equality (Allwood, 2013; Debusscher, 2011; Debusscher and van Der Vleuten, 2012).

While we agree with these views, the analysis here is less concerned with clarification on effectiveness of EU policies on gender in external action than with understanding the implications of the decision to seize the key world-wide and comprehensive EU initiative on gender: the Spotlight Initiative. In what follows, we propose a deeper critical interrogation that takes us to the heart of what meanings gender equality and women's empowerment assume in the context of EU external policies in post-conflict countries. Focusing on current EU efforts on ending gender and sexual based violence around the world through the Spotlight Initiative allows us to capture how the EU mobilises gender equality discourse to strengthen resilience and intervene incessantly.

The policy framework for the implementation of gender mainstreaming and gender equality policies in external action is set out in two key documents. The first is the New Strategy on Women, Peace and Security, signed at the end of 2018 by the European Council. The strategy replaces the Comprehensive approach on EU implementation of the United Nations Security Council Resolution 1325 and 1820 on Women, Peace and Security and is directly situated under the responsibility of the EEAS and under CSDP. The document sets out the basic principles to mainstreaming gender in operations related to crisis management, peacebuilding and peacekeeping, all this across different policy areas, from statebuilding to women's participation, to the protection of women from sexual and gender-based violence. The second document is the Gender Action Plan (GAP) II: 'Gender Equality and Women's Empowerment: Transforming the lives of girls and women through EU external Relations'. This document has the horizontal objective of transforming the gender-blind institutional culture of EU external relations.

Although these are 'both relevant policy frameworks for eliminating all forms of discrimination and violence that women and girls suffer from' (Council of the European Union, 2018), it is not a coincidence that the Spotlight Initiative is born not as part of the Comprehensive approach or the New Strategy on Women, Peace and Security, but as the tool through which to implement the first thematic objective of the GAP II - ensuring girls' and women's physical and psychological integrity - and situated in the European Commission Directorate General for Development Cooperation. The Women, Peace and Security agenda is perceived as an instrument directed at incorporating gender in peacekeeping and immediate postconflict transition, and therefore as a tool to be mobilised in very specific and time-bound contexts which enable quick emergency action (Deiana and Mcdonagh, 2018). By contrast, the Gender Action Plan II presents a new transformative approach that clearly resonates with resilience. The GAP seeks sustainable change in women's empowerment and gender equality in partner countries - admittedly, a very complex and lengthy process that necessitates for a longterm and persistent engagement of the EU in local and national policies. The GAP also seeks to demonstrate political commitments across regions and at all levels, collaborating with civil society actors and other international donors present on the ground, to influence the socio-cultural setting.

In May 2017, the European Union identified VAWG as a key priority for international cooperation and development policy, announced its plan to launch a global initiative on VAWG 
with the UN as its main implementing partner, and provided an initial financial envelope of EUR 500 million. Spotlight, the multilateral initiative, is seen as marking the beginning of a new way of engaging with the world, a much more 'comprehensive, evidenced-based, multilateral and holistic approach that works through persuasion mechanisms and a privileged partnership with civil society' (Interview \#1).

Indeed, the interviews carried out with EU personnel engaged in the planning and monitoring of the Spotlight Initiative offer an understanding of gender policies that reflects the EU external engagement paradigm shift from statebuilding to resilience. One of the policy leaders of the initiative in Brussels explained that there were three main reasons for the launch of Spotlight together with the UN, and the first one is the need to adapt to a changing world: 'First of all, the world is changing. We see that multilateral partnerships, working together, are issues that are not trendy in the world of today. We see how some leaders... are against it. So for the EU it was important to show support towards multilateralism' (Interview \#4).

The second reason is to help the United Nations implement its new integrated approach on the field - the Delivering as One - that is intended to provide with more coherence and efficiency in humanitarian, peacebuilding and development activities: 'Secondly, it was our way to demonstrate our support to the big reform process within the United Nations, as they try to work more as One UN' (Interview \#4) and 'the Spotlight is the "guinea-pig" for the reform' (Interview \#3).

The third reason is purely pragmatic. Such a Herculean enterprise calls for expert knowledge and boots on the ground:

'the UN is everywhere. Spotlight is a programme which has world-wide scope, and the UN has the expertise in the area, has the contacts, but also has the presence in many countries. So we felt that it would be a good partner to work on this ambitious enterprise. And it is of course very important to as a joint communication that we work together and stay together for the implementation of the SDGs [Sustainable Development Goals] and the Agenda 2030' (Interview \#4).

In response to this complex and changing world and the consequent need of 'doing gender' in a far-reaching way, the Initiative proposes six core areas of action to centre on prevention, capacity building and analysis: 'Spotlight Initiative, with dedicated large-scale resources, comprehensive design and focus, and evidence-based programmatic theory of change, will allow for intensified and focused action in strengthening core areas of action, which include: legislation/policies, institutions, prevention, delivery of, and access to, services, and data collection, disaggregation and sharing' (UNDP, 2017). Spotlight, therefore, highlights the need for a comprehensive approach to deal with a very complex problem. This 'new way of working' (EU and UN, 2018: 17), in which political buy-in and national ownership - engaging with civil society and a multistakeholder, collaborative approach - are key, serves to diffuse responsibilities and lower expectations as towards what the EU can achieve in terms of exporting gender equality. The EU accepts it cannot do this alone, and hence local and international partners need to share the responsibility.

Relatedly, the initiative constitutes a bottom-up attempt to facilitate the resilience of individuals and communities. For so doing, the EU focuses on the central principle of 'leaving no one behind', that speaks to the idea of overall inclusion and empowerment through capacity building and awareness raising activities. In particular, interventions are directed to 'all women and girls, 
particularly those facing multiple and intersecting forms of discrimination, including women and girls living in rural areas, from indigenous communities and ethnic minorities, living with HIV/AIDS, living with disabilities, LBTQI persons'. Once empowered, it is understood, these vulnerable women will be able to use their tacit knowledge to help transform their local communities and cope with future human and environmental catastrophes. Promoting gender equality, therefore, becomes a tool to achieve resilient communities (Rothe, 2017), as empowered women will exercise leadership in their communities and will become independent and entrepreneurial agents of change.

Furthermore, Spotlight reproduces gender hierarchies, in which women are victims to be empowered and men and boys are agents and partners on this empowerment process, while they are never considered as victims of violence. For example, the African Regional Investment Plan announces that 'men and boys will be specifically involved, as well as traditional and community leaders, to understand and address prevailing social norms and prevent SGBV [sexual and gender-based violence] and HP [harmful practices]. The identification of "champions" throughout the region will be a best practice replicable across the continent' (EU and UN, 2018a: 27). Such an approach has the risk of re-essentialising gender and gender relations, going against what is precisely the main objective of the Initiative.

The resilience discourse present in the Spotlight Initiative also shifts the focus from external threats to immanent risks and vulnerabilities. There is therefore a need to be flexible and adapt to the norms and culture of every particular society. Spotlight does so by proposing regional and national programmes based on one type of violence and focus areas as entry points to combat VAWG. While the focus in Africa will be on sexual and gender-based violence and harmful practices, it will concentrate on trafficking and sexual and labour exploitation in Asia, and on feminicide and family violence in Latin America and the Caribbean. The logic is, of course, that these generalisations problematize the vulnerabilities of societies and of women in the Global South as unrelated to the gendered structures of social and economic impoverishment or to the global capitalist dynamics of accumulation and dispossession. In this way, gender-based violence is treated as a cultural problem of the host region, while portraying the EU and the UN as civilising powers 'protecting brown women from brown men' in third countries (Spivak, 2010). Indeed, the Spotlight 2018 Annual Report includes a quote by Federica Mogherini, High Representative of the Union for Foreign Affairs and Security Policy proves so: 'We will engage beyond governments with civil society organizations and local communities. This is not going to be the traditional development aid because a change in attitudes, a change in culture, a change in lives can only grow from the heart of every society and community' (EU and UN, 2018: 24). The focus on gender injustices in developing countries to change harmful values and cultures seems to justify a long-term external engagement.

In order to replace external forceful intervention by long-term collaboration, there needs to be national government buy-in and commitment: 'The initiative will build, from the outset, strong political commitment from the highest levels of government in target countries and beyond, guaranteeing sustainability through the dedication of national attention, action, and resources' (Spotlight Initiative Fund, 2019). Government buy in and national ownership become therefore a condition sine qua non for participating in Spotlight, as the EU realises that it is impossible to succeed with universalist and externally imposed strategies:

We also attach a lot of importance to national ownership, to ensure sustainability we need to work with the government and with organisations on the spot, so we really work with a 
bottom-up approach. The headquarters do not tell us what to do. The programmes are really being done on the ground, in the countries concerned. And as I said we really count on civil society, not only in the implementation but also throughout the whole process of the initiative (Interview \#4).

The EU buys into local ownership and relies on existing capacities, but still offers advice and expertise, often influencing the set of benchmarks and standards; it intervenes vicariously, from afar (Joseph, 2014; Schmidt, 2015). Rather than an intrusive body, thus the EU appears to be invited and becomes a network facilitator while the burden of responsibility is increasingly handed over to national partners (Krogstad, 2014).

Furthermore, the EU is interested in going further than just building peace. Rather, the focus is on transformative long-term interventions: 'With Spotlight we don't work with countries in war. That is something that was excluded since the beginning. As we want to have a transformative approach we need to have capacity on the spot, we need to have buy-in' (Interview \#4). This of course goes back to the need to place more emphasis in working with civil society (Tocci, 2011), and in particular, with women's organisations that are privileged partners:

'I have been working for 20 years in Development Cooperation and it is the first time that I have seen a project like this, where we go that far in consultations, and so we do consultations with governments, with civil society, with a lot of stakeholders. I mean civil society remains a privileged partner throughout the whole process. We are informing them, they are also part of the governance structure... so we do not need to reinvent the wheel, but to try to build on good factors that are there already, work with partners we have worked with, communities,... so it is really working with what is there already, because a lot of good things are done already' (Interview \#4).

The emphasis on working with 'what is there already', with civil society and women's organisations capacities, shows again that resilience requires strong networks and partnerships. It demands that the EU intervenes further, providing these 500 million euros of support and offering the 20 years of cumulated knowledge on development cooperation through training, monitoring, evaluating.

The gargantuan task of achieving the objective of zero violence against women and girls around the world and on building strong women's organisations is one that requires sustained efforts and engagement. Spotlight is nothing more than the beginning of a long-term engagement process: 'But of course the objective of Spotlight is the elimination of violence against every woman and every girl and we apply the no one left behind principle. But you have to see what is possible in the period 5 years' (Interview \#4). As if building another Great Wall of China, this is a slow process that will require of particular attention, endurance and efforts from future generations: 'And I do think that when we look at gender we come from far; we are still not there, there is still a lot of work to do, but I definitely see progress, people take it into account, it is being discussed' (Interview \#4).

The documents and interviews analysed in this section reveal an obsession with developing a more-integrated, bottom-up, interconnected and coordinated approach based on key principles such as national ownership, leave no one behind, CSOs engagement and deliver as one. All these principles imply that the EU is willing to play a secondary role and step aside, although it casts a long shadow. It has become a connector and coordinator from afar, while multiple local actors use UN programmes to learn to be inclusive and tolerant. The Spotlight Initiative is, 
paradoxically, the symbol of a renovated normative power Europe, with a strong commitment towards ending gender and sexual violence worldwide, while at the same time doing so in a way that is detached and uncompromising. As Joseph puts it: 'resilience gives the impression of being part of an integrated and holistic strategy, without there actually being one. The resilience discourse is paradoxically more holistic and less engaged' (Joseph, 2018: 163).

The next section focuses on the case study of Liberia, where the Spotlight Initiative will dedicate 16 million euros, several months after the United Nations Mission to the country closed its doors. The argument is that the EU and the UN locate the source of the problem and of the solution in the socio-cultural settings of Liberia and use partnerships and focus on prevention measures to prolong supervision duties ad infinitum.

\section{Spotlight in Liberia: partnerships and prevention to intervene uninterruptedly}

Liberia has been chosen as one of the first African countries in which the Spotlight Initiative is implemented. In its latest Annual Human Rights report of 2017, the EU indicates that in light of the end of UNMIL, 'sexual and gender-based violence continues to be a major challenge for Liberia, as does addressing the shortfalls in the justice system, including the poor prison conditions that result from large numbers of pre-trial detainees' (EU, 2018). The report confirms as well that topics raised during the annual EU-Liberia Political Dialogue included FGM and gender-based violence and that two out of the four EU funded projects via the European Instrument for Democracy and Human Rights (EIDHR) are directed at combatting sexual and gender-based violence. However, this new emphasis on FGM and gender-based violence is remarkable, as the latest National Indicative Programme (2014-2020) that regulates the relationship between the EU and Liberia only contains two general phrases related to gender and the participation of women and vulnerable groups in employment creation in rural development and infrastructure. The turn towards prioritising gender-based violence and selecting Liberia as a Spotlight priority country seemed sudden and unexpected, as confirmed as well by our interviewees at the EU Delegation (Interview \#1, \#2 and \#5).

Also in the field there is a generalised feeling that Liberia did not comply with the primary and secondary indicators for country selection. First, interviewees indicated that they were surprised that Liberia was selected amongst the eight countries to receive support because they do not think it is one of the top 8 problematic countries regarding VAWG in Africa (primary indicators). They sense that there was 'a strong lobby from the UN side to get the green light to Liberia and cover the gap of UNMIL in terms of funding. Furthermore, contrary to what interviewees in Brussels indicated (Interview \#3 and \#4), they do not believe that there is enough buy-in from the government, or the capacity in the government and in civil society organisations to implement the reforms required in (secondary indicators). For example, one interviewee questioned whether the EU should invest so much in Liberia: 'there is a lack of political commitment; the government is not really backing the initiative ... In Liberia the President does not want to even sign an executive order prohibiting FGM' (Interview \#2). Furthermore, when asked then who would be their main partners, our interviewees indicated that local organisations are very much disorganised, and that there has been silence and lack of reaction from women's organisations on the fact that President Weah is delaying the signature of the Executive Order banishing FGM. 
Despite the fact that Liberia does not seem to comply with the indicators for country selection, the EU and the UN are determined to intervene. By examining the official country programme of the Liberia Spotlight Initiative and relying on our interviews, in this final section we seek to fathom the logic of an intervention designed to have no clear end point: first, we note how the EU and the UN locate the source of the problem and of the solution in the informal settings of Liberia, thus legitimising a holistic approach of changing social and cultural norms and behaviours, where women are key agents; second, we disaggregate how the intervention builds upon plural and comprehensive partnerships and focuses on prevention and response tasks to act uninterruptedly. We conclude that this approach is problematic to the extent that foreign powers both deny the autonomy of the local population and their own power and responsibility.

While Spotlight aims at eradicating femicide in Latin America, domestic violence in the Pacific and informal economies in Asia, the most problematic aspect of Liberian society, as in other subSaharan countries, are harmful traditional practices, such as FGM, 'a deeply rooted practice that is a few thousand years old' (Middelburg, 2018: 22). Besides the highly racialised and essentialist division of regional pathologies, what is highlighted here is that according to the UN and the EU all these problems and solutions are related to the socio-cultural fabrics of the countries intervened upon. As one of the reports influencing Spotlight concludes:

The main difficulty with the practice of FGM/C is that cultural change is required, people in Liberia who practice FGM/C see it as their culture. Cultural (and social) norms, practices and traditions need to change, as well as patriarchal attitudes and deep-rooted stereotypes regarding the roles, responsibilities and identities of girls and women in the family and society (Middelburg, 2018: 22).

No matter how ill or backward is the culture considered to be, the report also concludes that solutions cannot be exported and 'community ownership needs to be ensured for sustainability' (Middelburg, 2018: 22). Within informal spheres of local communities, women - illiterate women, women living with HIV-Aids, rural women - are considered as the most vulnerable individuals to local harmful practices and those suffering the most. At the same time, however, they are key community builders in their roles as civil society participants and economic producers.

Thus, LSI puts emphasis on 'a number of sociocultural factors that pose a challenge to the eradication of GBV in Liberia', like 'patriarchal norms', the legacy of the civil wars or 'a generalised cultural and societal acceptance of violence against women and children' (EU and UN, 2018b: 9). To be sure, the report silences the ways in which UN peacekeepers for example were implicated in SGBV and sexual abuse or the ways in which current EU trade and development policies regarding European concession companies are implicated in violence against women and girls. Instead, the key focus is on their culture: customs, values, rites and spirits. For example, FGM is related to 'a spiritual dimension' led by traditional leaders called Zoes who preserve a culture present in the region for centuries: 'in order to join the Sande society, which represents a rite of passage towards adulthood, women and girls need to undergo several initiation rituals, the most significant of which is FGM' (EU and UN, 2018b: 9). One of the consequences is that girls then are sent to 'bush schools' and miss official education.

If problem and solution lie in the socio-cultural settings of Liberia, intervention cannot be quick and targeted, as if made with a scalpel in a surgical procedure. Instead, two key programmatic innovations are attempted in Spotlight, which denote relentlessness. The first is the comprehensive approach which consists of building meaningful, sustained and diverse 
partnerships in different policy areas. Spotlight boasts about developing the LSI in a highly consultative process and is committed to planning, implementing and monitoring in a multistakeholder partnership that involves in a participatory manner five UN agencies (UN Women, UNFPA, UNDP, UNICEF and OHCHR), the EU and other INGO's, as much as the government, multiple civil society organisations, women's right groups, social movements, nonformal institutions and the private sector (EU and UN, 2018b: 13, 33). Thus the objective of leaving no one behind also feeds the project methodology and LSI works with 'the groups who are responsible for reproducing stereotypes on VAWG: rural, illiterate and the poorest women and girls; and rural, illiterate and the poorest men, especially young men aged 13-19 years' (EU and UN, 2018b: 55). LSI cooperates and creates synergies between men, boys, women's groups and the National Council of Chiefs and Elders, the Paramount Chiefs and Traditional leaders to become agents of change (EU and UN, 2018b: 58). Spotlight tries for example advance on the prevention of sexual exploitation of women and girls in their workplaces by cultivating publicprivate partnership regulatory frameworks with the concession companies in the counties where Spotlight will be operating and the EU, which has funded projects on the cocoa sector.

Ultimately, the purpose of 'an inclusive and multi-stakeholder process' is 'to build consensus and ownership' (EU and UN, 2018b: 15). This guarantees 'the holistic growth and well-being of woman and girl survivors of SGBV/HPs [Harmful Practices] in various domains: health, education, knowledge of their rights, leadership, social relations and resilience' (EU and UN, 2018b: 55). There is a gendered rationality underpinning these partnerships, where local women's tacit knowledge must be brought to the fore. As one of its main activities, the LSI will empower adolescent girls through 'livelihood support and essential life skills, mentorship and coaching on SRHR [sexual and reproductive health rights] and negative cultural practices, and ensuring information is disseminated to them on their rights in order protect themselves from SGBV/HPs and promote SRHR' (EU and UN, 2018b: 55).

The second programmatic innovation of the LSI is a 'prevention strategy' to counter the stereotypes, norms, attitudes and behaviour that harm women and girls:

The programme will place significant focus on prevention and response through in-school and out-of-school interventions by working with health and education stakeholders to build trust and confidence with informal decision makers and non-government institutions to stop the practice of FGM, while also advocating to strengthen other social and cultural practices within communities and working with formal and informal justice systems (EU and UN, 2018b: 15).

Prevention efforts are centred on cultivating 'the local level' and finding 'sustainable communitydriven solutions' with 'grass roots and hard-to-reach communities' before new episodes of violence against women and girls take place (EU and UN, 2018b: 19). The assumption is that if community members are empowered and aware of rights, responsibilities and consequences of certain practices and there is a strengthening of a positive cultural heritage, norms, attitudes and behaviours, 'then harmful social norms and practices and other forms of GBC will be prevented and eliminated' (EU and UN, 2018b: 19).

As seen in the first section, prevention cannot be confused with traditional framings of prevention that sought to counter the escalation of conflict in the highest corridors of power, by the means of exercising diplomatic action. Instead, Spotlight understands prevention as a commitment to work from the bottom up, within the informal spheres of Liberia: 'Interventions will focus on creating behaviour and social norm changes to foster sociocultural conditions that 
will prevent SGBV, teenage pregnancy, FGM and child marriage' (EU and UN, 2018b: 20). In the report, prevention and response to VAWG appear as joint efforts to constantly work with community structures and norms, thus ensuring long-term sustainability. Prevention seems to authorise to act all the time and everywhere, legitimising a permanent vigilance and transformation of the social milieu.

In sum, it is because of the need for inclusive partnerships and a comprehensive prevention strategy to address gender violence, that international intervention in Liberia is persistent and long-term. The project of eliminating violence against women and girls instils a complex temporality (Cavelty et al., 2015), characteristic of resilience projects. That is, traumatic events such as war and cases of rape in the past do not determine anything and cannot help us much but appear as ever-present menaces. Facing an uncertain future, all is left is a present that is saturated with tasks and duties that seem impossible to achieve. What propels Spotlight thus is 'hope' that a better future is in the making. Practitioners do not know how or when this harmonic future will be, and those in the field admit to lack the mechanisms to attain it. Provided that 'without the possibility of hope' interventions would neither be possible nor necessary (Chandler, 2019), hope is sustained to keep programmes and initiatives alive. In post-UNMIL Liberia, the hope of building resilient women's organisations and gender-sensitive local and national governments becomes, therefore, a justification for maintaining a strong EU and UN presence with no ending date in mind: 'Of course we know we won't stop all violence against women within 5 years because you know as well as I do that it will take more than 5 years, probably a generation. We all know that. Changing mindsets, changing habits. So these are not things that can be done from one day to the other. So let's say that Spotlight is a step in the right direction' (Interview \#4).

\section{Toward a conclusion: Spotlight and the denial of autonomy and responsibility}

This article has used Spotlight to shed light on the broader tendency to enhance community resilience and prolong interventions in post-conflict countries once peacekeeping tasks seem to have ended. In Liberia, Spotlight aspires to leave no woman and no girl behind through the elimination of harmful practices and sexual and gender-based violence, while focusing on the process of building inclusive partnerships, and developing prevention and response tasks to address the socio-cultural pathologies of the population. Resilience in the new sustaining peace paradigm could be understood as much as an effort to equip vulnerable populations with tools to mitigate the effects of poverty, discrimination and lack of opportunities, than as an opportunity for the international community to transvaluate past failures, privilege presentism and long-term processes and sustain hope to keep on waiting for another, better future.

In this conclusion, we seek to suggest that this sustained mode of intervention carries two negative implications. The first is that women and women's organisations continue to lack agency. They are and they will ever be merely 'implementers' of a programme that is not theirs: 'Priority will be given to building a critical mass of women and girls as key programme implementers, especially those from discriminated groups, including female students and women and girls from women's grass roots networks and academia' (EU and UN, 2018b: 55). In addition to building a critical mass of women and girls, women's organisations and governmental partners will receive capacity development support in order to form 'a coherent, inclusive, and empowered movement' (EU and UN, 2018b: 44), able to 'organize evidence-based advocacy campaigns to prevent SGBV/HPs and engage in coordinating, planning, developing and implementing multisectoral programmes/interventions' (EU and UN, 2018b: 18). In considering 
women as 'implementers', Spotlight furthers the tendency to portray gender and women in instrumentalist ways, which constrains women's empowerment and gender justice, as other feminist scholars have noted (Chant and Sweetman, 2012; Kunz, 2013; Roberts and Soederberg, 2012). Spotlight presupposes a deep-seated vulnerability of women and women's organisations, depoliticizing them and merely considering them 'implementers' of a global program, against which resistance is unconceivable.

Although it is undisputable that local organisations have been involved in different phases of the project, the assumption is that there are harmful values and social practices that Liberians cannot change alone, without external support. Autonomy of the people in Liberia contracts, as they are perceived as ill-equipped, underdeveloped or as having social pathologies, and the thus need for further support and guidance is rarely questioned (Bargués-Pedreny and Randazzo, 2018). Despite the end of peace-related responsibilities, the EU and the UN have found a new programme where they are indispensable to bring people together to collaborate. As one of our interviewees put it, 'fifteen years have passed since the end of the war, and now it is time for development cooperation and partnership. We have to get ourselves out of the peacebuilding mentality' (Interview \#2). Partnerships and cooperation are privileged over achieving specific results. And partnerships are still done in a very gendered way, by portraying international agencies as masculine protectors that limit the country's autonomy until the day they achieve the objective of leaving no one left behind. That'll be the day!

This brings us to the second implication: the role of permanent companions that the EU and UN have found in Liberia becomes worrying to the extent that they deny their responsibility. The LSI implies that the EU is exercising a form of normative power through persuasion and diffusion, not through imposition, and that ultimately success depends on the receiving country and society. By considering local actors and their culture to be both the problem and solution to address gender violence, Spotlight places the burden of the mission on them. The focus on national ownership, multi-stake holder partnerships and prevention measures point to local solutions but omit that problems may have an international origin. The emphasis on the present also shuns historical perspectives and international political economy questions.

It is necessary to see that the UN has lowered the expectations by replacing UNMIL with Spotlight. Leaving no one behind seems an ambitious quest, but its partial accomplishments do not depend on external agencies. The financial contribution and technical knowledge that is provided can only help if local partners act suitably or abide by the rules of the programme: 'It is up to your national partner that you are supporting to take the lessons learn and move forward. That's not only the responsibility of the EU or other development partner, even though there is a degree of responsibility towards your partner, of course' (Interview \#2). Since final success or a 'happy ending' is unviable, at least in a foreseeable future, the small victories will be formalized and recognized via 'memorandums of understanding or via a Gender Equality Champion Award' (EU and UN, 2018b: 56)'. External agencies never win or lose. Through Spotlight, from the distance, non-Western men and traditional harmful practices are responsible for violating women's rights while at the same time non-Western women and men can be gender champions and leaders of change, provided they remain under external, preventative guidance.

\section{Acknowledgments}


We would like to thank Ana Juncos, Jonathan Joseph, Devon Curtis and the participants in the EWIS workshop in Prague (Resilience and Hope in a World in Relation) for insightful comments and critiques. Also thanks to the journal editors and two generous reviews.

\section{Funding}

This work was supported by the Horizon 2020 Framework Programme [grant number 769886 and grant number 706888).

\section{ORCID}

Pol Bargués-Pedreny http:/ /orcid.org/0000-0002-9555-1934

Maria Martin de Almagro http://orcid.org/0000-0002-3760-0638

\section{Bibliography}

Allwood G (2013) Gender Mainstreaming and Policy Coherence for Development: Unintended Gender Consequences and EU Policy. Women's Studies International Forum 39: 42-52.

Bargués-Pedreny P (2018) Deferring Peace in International Statebuilding: Difference, Resilience and Critique. London and New York: Routledge.

Bargués-Pedreny P and Randazzo E (2018) Hybrid peace revisited: an opportunity for considering self-governance? Third World Quarterly: 1543-1560.

Campbell S, Chandler D and Sabaratnam M (2011) A Liberal Peace? The Problems and Practices of Peacebuilding. London and New York: Zed Books.

Cavaghan R (2017) Making Gender Equality Happen: Knowledge, Change and Resistance in EU Gender Mainstreaming. London: Routledge.

Cavelty MD, Kaufmann M and Søby Kristensen K (2015) Resilience and (In)Security: Practices, Subjects, Temporalities. Security Dialogue 46(1): 3-14.

Chandler D (2014) Resilience: The Governance of Complexity. London: Routledge.

Chandler D (2019) The Death of Hope? Affirmation in the Anthropocene. Globalizations: 1-12.

Chant S and Sweetman C (2012) Fixing Women or Fixing the World? 'Smart Economics', Efficiency Approaches, and Gender Equality in Development. Gender \& Development 20(3): 517-529.

Council of the European Union (2018) Council Conclusions on Women, Peace and Security. 15086/18. Available at: https://www.consilium.europa.eu/media/37412/st15086en18.pdf (accessed 15 February 2019).

David M and Guerrina R (2013) Gender and European External Relations: Dominant Discourses and Unintended Consequences of Gender Mainstreaming. Women's Studies International Forum 39(C): 53-62.

de Coning C (2018) Adaptive Peacebuilding. International Affairs 94(2): 301-317.

Debusscher P (2011) Mainstreaming Gender in European Commission development Policy: Conservative Europeanness? Women's Studies International Forum 34(1): 39-49.

Debusscher P and van Der Vleuten A (2012) Mainstreaming gender in European Union development cooperation with sub-Saharan Africa: promising numbers, narrow contents, telling silences. International Development Planning Review 34(3): 319-338.

Deiana M-A and Mcdonagh K (2018) Translating the Women, Peace and Security Agenda into EU Common Security and Defence Policy: Reflections from EU Peacebuilding. Global Society 32(4): 415-435. 
Duflo E (2012) Women Empowerment and Economic Development. Journal of Economic Literature 50(4): 1051-1079.

EC (2013) The EU's Comprehensive Approach to External Conflict and Crises. JOIN(2013) 30 final. Brussels: European Commission. Available at: https://europa.eu/capacity4dev/publicfragility/document/eus-comprehensive-approach-external-conflict-and-crises-5.

EC (2017) 2017 Joint Communication - A Strategic Approach to Resilience in the EU's External Action. JOIN(2017) 21 final. Brussels: European Commission. Available at: https://ec.europa.eu/europeaid/2017-joint-communication-strategic-approachresilience-eus-external-action_en.

EEAS (2015) The European Union in a Changing Global Environment: A More Connected, Contested and Complex World. Brussels: European Union External Action. Available at: https://europa.eu/globalstrategy/en/european-union-changing-global-environment.

EEAS (2016) Shared Vision, Common Action: A Stronger Europe: A Global Strategy for the European Union's Foreign And Security Policy. European Union Global Strategy. Available at: http://europa.eu/globalstrategy/en.

Ejdus F and Juncos AE (2018) Reclaiming the local in EU peacebuilding: Effectiveness, ownership, and resistance. Contemporary Security Policy 39(1): 4-27.

EU (2018) EU Annual Human Rights Report: Liberia country update. Available at: https://eeas.europa.eu/delegations/liberia_id/45530/ EU Annual Human Rights Report: Liberia country update.

EU and UN (2018) Spotlight Initiative: To Eliminate Violence against Women and Girls. Annual Report, 1 July 2017-31 March 2018. European Union and United Nations. Available at: http://www.un.org/en/spotlightinitiative/assets/pdf/Spotlight_Annual_Report_July_2017-March_2018.pdf.

EU and UN (2018a) Spotlight Initiative. Annex I c. Regional Investment Plan Africa and 8 country programme profiles Liberia, Malawi, Mali, Nigeria, Niger, Mozambique, Uganda, Zimbabwe, 2018 2023. EU and United Nations. Available at: mptf.undp.org/document/download/21006.

EU and UN (2018b) Spotlight Initiative. Country Programme Document Liberia. Available at: http://mdtf.undp.org/document/download/21123.

Ghani A and Lockhart C (2008) Fixing Failed States: A Framework for Rebuilding a Fractured World. Oxford: Oxford University Press.

Guerrina R (2005) Mothering the Union: Gender Politics in the EU. Manchester: Manchester University Press.

Guerrina R and Wright KAM (2016) Gendering Normative Power Europe: Lessons of the Women, Peace and Security Agenda. International Affairs 92(2): 293-312.

Guerrina R, Chappell L and Wright KAM (2018) Transforming CSDP? Feminist Triangles and Gender Regimes. Journal of Common Market Studies 56(5): 1036-1052.

Hirblinger A and Landau D (2018) Governing Conflict: The Politics of Scaling Difference. Journal of Intervention and Statebuilding 12(3): 385-404.

Hoskyns C (1996) Integrating Gender: Women, Law and Politics in the European Union / Catherine Hoskyns. London: Verso.

Hughes C and Pupavac V (2005) Framing Post-conflict Societies: International Pathologisation of Cambodia and the post-Yugoslav States. Third World Quarterly 26(6): 873-889.

Hunter L (2016) Environmental Change, Migration, and Gender - Population Reference Bureau. Available at: https://www.prb.org/environment-gender/ (accessed 14 February 2019).

Joseph J (2014) The EU in the Horn of Africa: Building Resilience as a Distant Form of Governance. Journal of Common Market Studies 52(2): 285-301. 
Joseph J (2018) Varieties of Resilience: Studies in Governmentality. Cambridge: Cambridge University Press.

Juncos AE (2017) Resilience as the new EU foreign policy paradigm: a pragmatist turn? European Security 26(1): 1-18.

Juncos AE and Joseph J (2020) Resilient Peace: Exploring the Theory and Practice of Resilience in Peacebuilding Interventions. Journal of Intervention and Statebuilding 14 (3): 289302.

Kirby P and Shepherd LJ (2016) The Futures Past of the Women, Peace and Security Agenda. International Affairs 92(2): 373-392.

Kristjanson P, Bryan E, Bernier Q, et al. (2017) Addressing Gender in Agricultural Research for Development in the Face of a Changing Climate: Where are We and Where should We be going? International Journal of Agricultural Sustainability 15(5): 482-500.

Krogstad EG (2014) Local Ownership as Dependence Management: Inviting the Coloniser Back. Journal of Intervention and Statebuilding 8(2-3): 105-125.

Kronsell A (2006) Methods for Studying Silences: Gender Analysis in Institutions of Hegemonic Masculinity. In: Ackerly B, Stern M, and True J (eds) Feminist Methodologies for International Relations. Cambridge: Cambridge University Press.

Kunz R (2013) Governing International Migration through Partnership. Third World Quarterly 34(7): 1227-1246. DOI: 10.1080/01436597.2013.825089.

Lemay-Hébert N (2011) The "Empty-Shell” Approach: The Setup Process of International Administrations in Timor-Leste and Kosovo, Its Consequences and Lessons. International Studies Perspectives 12(2): 190-211.

Lindroth M and Sinevaara-Niskanen H (2019) Politics of hope. Globalizations: 1-5. DOI: 10.1080/14747731.2018.1560694.

Lombardo E and Meier P (2006) Gender Mainstreaming in the EU: Incorporating a Feminist Reading? European Journal of Women's Studies 13(2): 151-166.

Mackay F, Kenny M and Chappell L (2010) New Institutionalism Through a Gender Lens: Towards a Feminist Institutionalism? International Political Science Review 31(5): 573-588.

Martin de Almagro M (2018) Hybrid Clubs: A Feminist Approach to Peacebuilding in the Democratic Republic of Congo. Journal of Intervention and Statebuilding 12(3): 319-334.

Martin de Almagro M and Ryan C (2019) Subverting Economic Empowerment: Towards a Postcolonial-Feminist Framework on Gender (In)Securities in Post-War Settings. European Journal of International Relations.

Middelburg MJ (2018) Appraisal on FGM/C in Liberia: Suggestions for a Country Strategy Tackling FGM/C in the Spotlight Initiative. Maarsen: Middelburg Human Rights Law Consultancy.

Morillas P (2019) Strategy-Making in the EU From Foreign and Security Policy to External Action. Basingstoke: Palgrave Macmillan.

Olsson L and Gizelis T-I (eds) (2015) Gender, Peace and Security: Implementing UN Security Council Resolution 1325. London: Routledge.

Paris R and Sisk TD (2009) The Dilemmas of Statebuilding: Confronting the Contradictions of Postwar Peace Operations. London: Routledge.

Pratt N and Richter-Devroe S (2011) Critically Examining UNSCR 1325 on Women, Peace and Security. International Feminist Journal of Politics 13(4): 489-503. DOI: 10.1080/14616742.2011.611658.

Randazzo E (2016) The Paradoxes of the 'Everyday': Scrutinising the Local Turn in Peace Building. Third World Quarterly 37(8): 1351-1370.

Read R, Taithe B and Mac Ginty R (2016) Data hubris? Humanitarian information systems and the mirage of technology. Third World Quarterly 37(8): 1314-1331. 
Risse T and Börzel T (2018) Fostering Resilience in Areas of Limited Statehood and Contested Orders. EULISTCO's Conceptual Framework. Berlin.

Roberts A and Soederberg S (2012) Gender Equality as Smart Economics? A critique of the 2012 World Development Report. Third World Quarterly 33(5): 949-968.

Rothe D (2017) Gendering Resilience: Myths and Stereotypes in the Discourse on Climateinduced Migration. Global Policy 8(S1): 40-47. DOI: 10.1111/1758-5899.12400.

Ryan C and Basini H (2017) UNSC Resolution 1325 national action plans in Liberia and Sierra Leone: An analysis of gendered power relations in hybrid peacebuilding. Journal of Intervention and Statebuilding 11(2): 186-206. DOI: 10.1080/17502977.2017.1337337.

Schmidt J (2015) Constructing New Environments versus Attitude Adjustment: Contrasting the Substance of Democracy in UN and EU Democracy Promotion Discourses. Cambridge Review of International Affairs 28(1): 35-54.

Shepherd L (2017) Gender, UN Peacebuilding, and the Politics of Space: Locating Legitimacy. Oxford: Oxford University Press.

Shepherd LJ (2011) Sex, Security and Superhero(in)es: From 1325 to 1820 and Beyond. International Feminist Journal of Politics 13(4): 504-521.

Spivak G (2010) Can the Subaltern Speak? In: Reflections on the History of an Idea: Can the Subaltern Speak? New York City: Columbia University Press, pp. 21-80.

Spotlight Initiative Fund (2019) Trust Fund Factsheet. Available at: http://mptf.undp.org/factsheet/ fund/SIF00 (accessed 15 February 2019).

Tocci N (2011) The European Union, Civil Society and Conflict. Taylor \& Francis.

Tocci N (2018) Towards a European Security and Defence Union: Was 2017 a Watershed? Journal of Common Market Studies 56(S1): 131-141.

Tull DM (2018) The Limits and Unintended Consequences of UN Peace Enforcement: The Force Intervention Brigade in the DR Congo. International Peacekeeping 25(2): 167-190.

Turner M (2011) Creating 'Partners for Peace': The Palestinian Authority and the International Statebuilding Agenda. Journal of Intervention and Statebuilding 5(1): 1-21.

UN (2017) Liberia Transition Multi Partner Trust Fund. United Nations. Available at: https://www.undp.org/content/dam/unct/liberia/img/documents/Draft_TOR_Liberi a\%20Transition_MPTF_revised_with_NY_comments_1_December_2017.pdf.

UN (2018a) Peacebuilding and Sustaining Peace: Report of the Secretary-General. A/72/707-S/2018/43, 18 January. General Assembly and Security Council.

UN (2018b) Plan of Action for Religious Leaders and Actors. United Nations Office on Genocide Prevention and the Responsibility to Protect.

UN (2018c) United Nations Conflict Prevention and Preventive Diplomacy in Action: An Overview of the Role, Approach and Tools of the United Nations and its Partners in Preventing Violent Conflict. United Nations Department of Political Affairs. Available at: https://www.un.org/undpa/sites/www.un.org.undpa/files/Booklet_200618_fin_scrn.p df.

UNDP (2017) Trust Fund Factsheet. Spotlight Initiative Fund. Multi-Partner Trust Fund Office. Available at: http://mptf.undp.org/factsheet/fund/SIF00.

Verloo M (2007) Multiple Meanings of Gender Equality: A Critical Frame Analysis of Gender Policies in Europe. Central European University Press. Available at: https://muse.jhu.edu/book/40459 (accessed 15 February 2019).

Wagner W and Anholt R (2016) Resilience as the EU Global Strategy's new leitmotif: pragmatic, problematic or promising? Contemporary Security Policy 37(3): 414-430.

Wallis J, Jeffery R and Kent L (2016) Political Reconciliation in Timor Leste, Solomon Islands and Bougainville: the Dark Side of Hybridity. Australian Journal of International Affairs 70(2): 159-178. 
